\title{
Effect of Risk Factors and Habits on Preterm Labor At Women's Health hospital
}

\author{
Nagwa Abu Elmawaheb, Safwat Abd El-Rady, Manal Farouk Mustafa, Nadia Hussien Ahmed.
}

Nursing specialist, El Ganaiem Central Hospital.

Prof. of Obstetrics\& Gynecology, Faculty of Medicine, Assiut University.

Assistant Prof of Obstetrics\& Gynaecology, Faculty of Nursing, Assiut University

Lecturer of Obstetrics\& Gynaecology, Faculty of Nursing, Assiut University.

\begin{abstract}
Background: Preterm delivery account for $75 \%$ of perinatal mortality and more than half the long-term morbidity. Although most preterm babies survive are at risk of Neuro developmental impairments and respiratory complications. Aim of the study Determine the effect of risk factors and habits on preterm labor. Methods \& materials: Descriptive research design conducted in labor ward of Obstetrics \&Gynecology department, Women's Health Center, from the first of December 2012 to the end of May 2013, Convenience sample were 420 cases. Tools used; structured interviewing questionnaire sheet. It included Personal, Obstetrical, Medical history, risk factors, risky habits of preterm delivery .Results: The socio-demographic characteristics Show that mean age was (28.1 \pm 5.7$)$, Concerning to risk factors associated with pregnancy, $(29.8 \%)$ had preterm premature rupture of membrane, $(20.2 \%)$ had previous preterm delivery, Risk habits, $(61 \%)$ of the husband pregnant women had heavy smoke. (21.4\%) had a medical disorders such as (8.3\%) had diabetes mellitus. Conclusion: Many risk factors and habits such as previous preterm delivery, preterm premature rupture of membrane, smoking remains the most accurate predictors for subsequent preterm delivery. Recommendations: Women should be counsel about nutrition, rest, antenatal visit .
\end{abstract}

\section{Keywords: Preterm Delivery \& Preterm Premature Rupture Of Membrane.}

\section{Introduction}

Preterm birth is defined by ( Blencowe et al., 2012) as all births before 37 completed weeks of gestation or fewer than 259 days since the first day of a woman's last menstrual period. Preterm birth can be further sub-divided based On gestational age: extremely preterm ( $<28$ weeks), very preterm $(28-<32$ weeks) and moderate preterm $(32-<37$ completed weeks of gestation) . Moderate preterm birth may be further split to focus on late preterm birth (34 - <37 completed weeks).

Preterm birth is a syndrome with a variety of causes which can be classified into two broad subtypes: (1) spontaneous preterm birth (spontaneous onset of labor or following prelabor premature rupture of membranes (pPROM)) and (2) provider-initiated preterm birth (defined as induction of labor or elective caesarian birth before 37 completed weeks of gestation for maternal or fetal indications. (Goldenberg et al., 2012).

Maternal history of preterm birth is a strong risk factor and most likely driven by the interaction of genetic, epigenetic and environmental risk factors (Plunkett \& Muglia, 2008).

Some lifestyle factors can contribute to spontaneous preterm birth include physical stressors such as shift work, long hours standing and heavy lifting have been consistently associated with increased risk of preterm birth, Behavioral stressors such as smoking, alcohol and illicit drug use, poor eating habits, sexual and physical activity, are of great importance as modifiable risk factors, as their elimination can lead to an effective reduction in the preterm birth rate. These behaviors pose specific challenges in establishing a cause and effect relationship because of their inherent complexity, (Mutambudzi et al., 2011).

Signs \& symptoms of preterm labour are bad cramps or stomach pains that don't go away, trickle or gush of fluid, or bleeding, from your vagina ,lower back pain/pressure, or a change in lower backache a feeling that the baby is pushing down ,contractions, or change in the strength or number of them ,an increase in the amount of vaginal discharge .(Liu et al., 2012).

Supportive nursing care is important to the woman in preterm labor during hospitalization. Promote bed rest, monitor vital signs, measure intake and output, monitor the fetal heart rate continuously, and monitor uterine contractions. Having the woman lie on her left side to facilitates maternal-fetal circulation. Keep vaginal examinations to a minimum. If tocolytic agents are being administered ,monitor the mother and fetus closely for any adverse effects.( Blencowe et al., 2012). 
Educational programs generally train women to recognize symptoms of preterm labor including contractions, pelvic pressure, and vaginal discharge. In addition, weekly vaginal examinations have been used in an attempt to detect early cervical changes before the onset of labor. ( March of Dimes Web site,2010)

\section{Significance of the study}

Of all early neonatal deaths (deaths within the first 7 days of life) that are not related to congenital malformations, $28 \%$ are due to preterm birth. Preterm birth rates have been reported to range from $5 \%$ to $7 \%$ of live births in some developed countries, but are estimated to be substantially higher in developing countries. The preterm estimate that $9.6 \%$ of all births were preterm in 2005, which translates to about 12.9 million births definable as preterm. Approximately $85 \%$ of this burden was concentrated in Africa and Asia, where 10.9 million births were preterm. (Lawn et al ., 2006).

In Egypt number of preterm births was 136,900 and preterm birth rate was $7.28 \%$ and deaths from complications was 8,100 .Thus, preterm birth is a global problem that requires collective and coordinated global action (Blencowe etal ,.2012).

\section{Research question}

There continue too many unanswered question as:

- What is the effect of risk factors during pregnancy on incidence preterm labor?

- What is the effect of risky habits during pregnancy on incidence preterm labor?

\section{Aims of the study}

The aim of study was to determine the effect of risk factors and habits on preterm labor at Women's Health Hospital .

\section{Subjects and Methods}

[

I- Research design

Descriptive research design was utilized in this study.

\section{II - Setting of the study}

This study was conducted in labor ward of Obstetrics \&Gynecology department, Women's Health Center, during the period from the first of December 2012 to the end of May 2013 .The emergency labor ward serves all cases of abortion and high-risk pregnancy. The labor ward consists of seven rooms, each having four beds. The ward has a nursing team of 34 members: 24 staff nurses, 4 assistant nurses, and 6 head nurses.

\section{II- Subjects}

Convenient sample of pregnant women at preterm labor seeking care at Women's Health Center was used .The sample of the present study included all women at preterm labor during the period from the first of December 2012 to the end of May 2013 ,the total numbers of preterm deliveries in this period were 420 cases.

\section{A convenient sample was included: Inclusion} criteria

1. All women in preterm labor (Delivery with less than 37 weeks of gestation).

2. All women in preterm labor with medical complication such as diabetes mellitus, hypertension, vaginal bleeding ...et c.

\section{Exclusion criteria}

All women in delivery with more than 37 weeks of gestation.

IV- Tools

The tool used for data collection consisted of structured interviewing questionnaire sheet developed by the researcher to collect the necessary data from the pregnant women based on relevant literature and reviewed by experts from obstetrics and Gynecological nursing specialties to determine effect of risk the factors and habits on preterm labor.

The questionnaire included the following items: 1-Socio-demographic characteristics of the studied sample such as:

- Name, age, education, occupation , marital status, place of work and residence.

- Data about their obstetrical history

- This includes the number of ( Gravidity, Parity, Abortion, still birth, living birth )if she had a history of previous induction of labor ,preterm PROM, obstructed labor, caesarean section, preterm labor, mode of delivery in last pregnancy, previous contraceptive use and type of method, et c).

- Data about their current pregnancy

- This pregnant women was asked about gestational age, complain, Diagnosed problem, Medical history, Diagnosed chronic disease, any complication associated with current delivery, as well as history of infection and medication taking during this pregnancy.

- The effect of risky factor and risky habits on preterm labor

- This includes data about:

- 1-Have any of this risk factor :

- Previous preterm birth ,Preterm premature rupture of membranes (PPROM),Cervical incompetence, Cervical surgical procedures, Uterine anomalies ,Multiple gestation , Polyhydramnios ,Oligohydramnios ,Placental abruption ,Vaginal bleeding ,Circulage, Placenta previa). 


\section{2- Risky habits}

Passive smoking, carry heavy object daily، standingfor long time (>1continuous hour) daily, heavy house work, use transportation.

\section{Fieldwork}

- Before conducting the study an official permission to carry out the study will be obtained from the responsible hospital authorities of directors in women health hospital, Assiut University and the head of obstetrics and gynecology department.

- The researcher introduced herself to the head of obstetrics and gynecology department and then the researcher introduced herself to the nurses working in the department and then the researcher trained the nurses to collect data and filling the questionnaire form.

- The interviewer greeted and introduced herself to the pregnant women, and explained the nature and the aims of the study, and then an oral consent to participate was obtained from each women which included the rights for privacy and confidentiality.

- The researcher collected the sample through six month, seven day per week and average range of cases in the day was from 2-3 cases.

- The researcher asked women the questions presented in the sheet and then filled the sheet for illiterate and educated pregnant women, interviewing the women to collect data related to the Socio demographic characteristics, obstetric history, current pregnancy, medical history, risk factor and risky habits .some time women need more explanation to clarify questions.

- Each interview took about 15-20 minutes with each pregnant woman.

\section{Limitaion}

- Limited number of literatures and researches about preterm labor in egypt.

- Number of preterm deliveries was limited .

\section{Administrative Design}

Before conducting the study an official permission to carry out the study was obtained from the responsible hospital authorities of directors in women health hospital, then an oral consent of the participate was obtained, women were reassured that any obtained information were used only for the purpose of the study, The study nature had no actual or potential harms on women and professional help was provided whenever needed.

\section{Ethical aspects}

There was no direct benefit to the women who participated in this study. However, the information we get from the study helped us in know the effect of risk factors and habits on preterm labor, there are no risks for participating in the study Any participant in the questionnaire had the right to refuse answering any of the questions or to stop the interview at any time. She also had the right to withdraw her data from the study immediately after the end of the interview, but, not after that as the data was left anonymous and we had no link between the name and the data after that. Women participation in the study had not positively or negatively affected the service they was received.

Statistical design

The collected data was coded, tabulated and analyzed using the statistical package for social science programs (SPSS) version 16 windows Microsoft .Continuous data was expressed as frequency, percentage, means and SD .Discrete data was expressed as frequency and percentage. Comparison between variables was made using probability (P-value), less than 0.05 was considered significant and less than 0.001 was considered highly significant. 


\section{Results}

Table (1): Distribution of the pregnant women according to their Socio-demographic Characteristics

\begin{tabular}{|c|c|c|}
\hline Socio-economic characteristics & No. $=420$ & $\%$ \\
\hline Age(year) Mean \pm SD & $28.1 \pm 5.7$ & \\
\hline $17-27$ & 207 & 49.3 \\
\hline $27-37$ & 191 & 45.5 \\
\hline $37-47$ & 22 & 5.2 \\
\hline \multicolumn{3}{|l|}{ Education } \\
\hline Illiterate & 8 & 1.9 \\
\hline Basic & 55 & 13.1 \\
\hline Secondary & 232 & 55.2 \\
\hline University & 125 & 29.8 \\
\hline \multicolumn{3}{|l|}{ Occupation } \\
\hline Housewife & 390 & 92.9 \\
\hline Working & 30 & 7.1 \\
\hline \multicolumn{3}{|l|}{ Residence } \\
\hline Urban & 285 & 67.8 \\
\hline Rural & 135 & 32.2 \\
\hline
\end{tabular}

Table (2): Distribution of pregnant women according to their Obstetric history.

\begin{tabular}{|c|c|c|}
\hline Obstetric history & No. $=420$ & $\%$ \\
\hline \multicolumn{3}{|l|}{ Gravidity } \\
\hline 1 & 109 & 25.9 \\
\hline $2-4$ & 207 & 49.2 \\
\hline $5+$ & 104 & 24.9 \\
\hline \multicolumn{3}{|l|}{ Parity } \\
\hline 0 & 137 & 32.6 \\
\hline $1-3$ & 167 & 39.8 \\
\hline $3-5$ & 106 & 25.2 \\
\hline+5 & 10 & 2.4 \\
\hline \multicolumn{3}{|l|}{ Abortion } \\
\hline 0 & 269 & 64 \\
\hline $1-3$ & 138 & 32.9 \\
\hline$>3$ & 13 & 3.1 \\
\hline \multicolumn{3}{|l|}{ Still birth } \\
\hline 0 & 395 & 94 \\
\hline 1 & 23 & 5.5 \\
\hline 2 & 2 & 0.5 \\
\hline \multicolumn{3}{|l|}{ Live birth } \\
\hline 0 & 137 & 32.6 \\
\hline $1-3$ & 225 & 53.6 \\
\hline$>3$ & 58 & 13.8 \\
\hline
\end{tabular}




\begin{tabular}{|l|c|c|}
\hline \multicolumn{1}{|c|}{ Obstetric history } & No. $=420$ & $\%$ \\
\hline Complian in previous pregnancy & 137 & 32.6 \\
\hline N0 & 33 & 7.9 \\
\hline Induction of labor & 15 & 3.6 \\
\hline Obstructed labor & 87 & 20.7 \\
\hline PROM & 30 & 7.2 \\
\hline Cesarean section & 79 & 18.8 \\
\hline Pre-term labor & 13 & 3.1 \\
\hline Midtrimester miscarriage & 17 & 4.0 \\
\hline Abortion & 9 & 2.1 \\
\hline Circulage & 116 & 27.6 \\
\hline Mode of previous delivery & 4 & 1.0 \\
\hline NVD & 163 & 38.8 \\
\hline Assisted & \multicolumn{1}{|l|}{} \\
\hline CS & 137 & 32.6 \\
\hline last delivery since (Years) & 138 & 32.9 \\
\hline Prime & 119 & 28.3 \\
\hline $1-2$ & 26 & 6.2 \\
\hline $3-5$ & \multicolumn{2}{|l|}{} \\
\hline+6 &
\end{tabular}

Table (3): Distribution of pregnant women according to their current Obstetric history.

\begin{tabular}{|c|c|c|}
\hline Current history & 420 & $\%$ \\
\hline \multicolumn{3}{|l|}{ Gestational age } \\
\hline $28-30$ & 38 & 9 \\
\hline $31-33$ & 38 & 9 \\
\hline $34-36$ & 344 & 82 \\
\hline \multicolumn{3}{|l|}{ Symptom of preterm labor } \\
\hline Abdominal pain \& Passage of fluids & 149 & 35.5 \\
\hline Abdominal pain \& Vaginal discharge & 51 & 12.1 \\
\hline Abdominal pain \& Vaginal bleeding & 31 & 7.4 \\
\hline Abdominal pain \& Lower back pain & 70 & 16.7 \\
\hline Abdominal pain \& Other symptom & 45 & 10.7 \\
\hline Vaginal bleeding \& Lower back pain & 74 & 17.6 \\
\hline \multicolumn{3}{|l|}{ Contraction } \\
\hline Yes & 304 & 72.4 \\
\hline None & 116 & 27.6 \\
\hline \multicolumn{3}{|l|}{ Current diagnosis } \\
\hline None & 226 & 53.8 \\
\hline Preeclampsia & 146 & 34.8 \\
\hline Malpresentation & 48 & 11.4 \\
\hline \multicolumn{3}{|l|}{ Mode of delivery } \\
\hline NVD & 85 & 20.3 \\
\hline Assisted & 1 & 0.2 \\
\hline $\mathrm{CS}$ & 334 & 79.5 \\
\hline
\end{tabular}


Table 4: Multiple regression analysis to assess the effect of risk factors on preterm labor.

\begin{tabular}{|c|c|c|c|c|c|c|c|c|c|}
\hline \multicolumn{2}{|r|}{ Variables } & \multirow{2}{*}{$\begin{array}{c}\mathbf{R} \\
0.73\end{array}$} & \multirow{2}{*}{\begin{tabular}{|l|}
$* \mathbf{R}^{2}$ \\
0.533 \\
\end{tabular}} & \multirow{2}{*}{$\begin{array}{c}\text { Contribution } \\
53.3 \%\end{array}$} & \multirow{2}{*}{$\begin{array}{c}\mathbf{F} \\
431.4\end{array}$} & \multirow{2}{*}{\begin{tabular}{|l} 
P. value \\
$0.001 * *$
\end{tabular}} & \multirow{2}{*}{$\begin{array}{c}\mathbf{B} \\
0.73\end{array}$} & \multirow{2}{*}{$\begin{array}{c}\text { Const. } \\
2.47\end{array}$} & \multirow{2}{*}{$\begin{array}{c}\begin{array}{c}\text { Prediction } \\
\text { equation }\end{array} \\
\text { Preterm= }=2.47 \\
+0.73 \mathrm{X} 1\end{array}$} \\
\hline$\frac{\overline{0}}{\infty}$ & $\begin{array}{l}\text { X1-Preterm premature } \\
\text { rupture of membranes } \\
\text { (PPROM) }\end{array}$ & & & & & & & & \\
\hline \multirow[t]{2}{*}{ 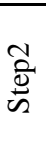 } & $\begin{array}{l}\text { X1-Preterm premature } \\
\text { rupture of membranes } \\
\text { (PPROM) }\end{array}$ & \multirow[t]{2}{*}{0.77} & \multirow[t]{2}{*}{0.593} & \multirow[t]{2}{*}{$59.3 \%$} & \multirow[t]{2}{*}{367.2} & \multirow[t]{2}{*}{$0.001 * *$} & 0.664 & \multirow[t]{2}{*}{2.34} & \multirow{2}{*}{$\begin{array}{c}\text { Preterm }=2.34 \\
+0.664 X 1+0.247 \\
\text { X2 }\end{array}$} \\
\hline & X2-Previous preterm birth & & & & & & 0.247 & & \\
\hline \multirow{3}{*}{$\frac{2}{\frac{2}{\omega}}$} & X1-Preterm premature & \multirow{3}{*}{0.81} & \multirow{3}{*}{0.656} & \multirow{3}{*}{$65.6 \%$} & \multirow{3}{*}{341.9} & \multirow{3}{*}{$0.001 * *$} & 0.557 & \multirow{3}{*}{2.16} & \multirow{3}{*}{$\begin{array}{c}\text { Preterm }=2.16 \\
+0.557 \\
\mathrm{X} 1+0.347 \mathrm{X} 2+ \\
0.214 \mathrm{X} 3\end{array}$} \\
\hline & $\begin{array}{l}\text { rupture of membranes } \\
\text { (PPROM) }\end{array}$ & & & & & & 0.347 & & \\
\hline & $\begin{array}{l}\text { X2-Previous preterm birth } \\
\text { X3-Vaginal bleeding }\end{array}$ & & & & & & 0.214 & & \\
\hline \multirow{5}{*}{$\frac{+}{\frac{0}{2}}$} & X1-Preterm premature & \multirow{5}{*}{0.84} & \multirow{5}{*}{0.706} & \multirow{5}{*}{$70.6 \%$} & \multirow{5}{*}{289.7} & \multirow{5}{*}{$0.001 * *$} & 0.498 & \multirow{5}{*}{1.98} & \multirow{5}{*}{$\begin{array}{c}\text { Preterm }=1.98+ \\
0.498 X 1+ \\
0.332 \mathrm{X} 2+0.287 \\
\mathrm{X} 3+0.114 \mathrm{X} 4\end{array}$} \\
\hline & $\begin{array}{l}\text { rupture of membranes } \\
\text { (PPROM) }\end{array}$ & & & & & & 0.332 & & \\
\hline & X2-Previous preterm birth & & & & & & & & \\
\hline & X3-Vaginal bleeding & & & & & & 0.287 & & \\
\hline & X4-Multiple gestation & & & & & & 0.114 & & \\
\hline \multirow{5}{*}{$\frac{2}{\frac{2}{4}}$} & X1-Preterm premature & \multirow{5}{*}{0.86} & \multirow{5}{*}{0.740} & & & & 0.475 & & \\
\hline & rupture of membranes & & & & & & 0.229 & & Preterm $=177+$ \\
\hline & (PPROM) & & & 7400 & 2753 & $\cap \Omega 01 * *$ & 0.214 & 177 & $0.475 \mathrm{X} 1+$ \\
\hline & $\begin{array}{l}\text { X2-Prev1ous preterm birth } \\
\text { X3-Vaginal bleeding }\end{array}$ & & & $74.0 \%$ & 275.3 & $0.001 \cdots$ & 0.187 & 1.77 & $0.229 \times 2+0.214 \times 3+$ \\
\hline & $\begin{array}{l}\text { X4-Multiple gestation } \\
\text { X5-Placenta previa }\end{array}$ & & & & & & 0.115 & & \\
\hline
\end{tabular}

Multiple logistic regression analysis

Table 5: Multiple regression analysis to assess the effect of risk habits on preterm labor.

\begin{tabular}{|c|c|c|c|c|c|c|c|c|c|}
\hline \multicolumn{2}{|r|}{ Variables } & \multirow{2}{*}{\begin{tabular}{|c|}
$\mathbf{R}$ \\
0.67 \\
\end{tabular}} & \multirow{2}{*}{\begin{tabular}{|l|}
$* \mathbf{R}^{2}$ \\
0.449 \\
\end{tabular}} & \multirow{2}{*}{$\begin{array}{c}\text { Contribution } \\
44.9 \%\end{array}$} & \multirow{2}{*}{\begin{tabular}{|c|}
$\mathbf{F}$ \\
375.2
\end{tabular}} & \multirow{2}{*}{$\begin{array}{l}\text { P. value } \\
0.001 * *\end{array}$} & \multirow{2}{*}{$\begin{array}{c}\text { B } \\
0.67\end{array}$} & \multirow{2}{*}{$\begin{array}{c}\text { Const. } \\
3.87\end{array}$} & \multirow{2}{*}{$\begin{array}{c}\text { Prediction equation } \\
\text { Preterm }=3.87 \\
+0.67 \mathrm{X} 1\end{array}$} \\
\hline क्षे & X1-Husband smoking & & & & & & & & \\
\hline \multirow{2}{*}{ 这 } & \multirow{2}{*}{$\begin{array}{l}\text { X1- Husband smoking } \\
\text { X2-Standing for long time }\end{array}$} & \multirow{2}{*}{0.74} & \multirow{2}{*}{0.548} & \multirow{2}{*}{$54.8 \%$} & \multirow{2}{*}{344.4} & \multirow{2}{*}{$0.001 * *$} & 0.52 & \multirow{2}{*}{3.46} & \multirow{2}{*}{$\begin{array}{c}\text { Preterm }=3.46 \\
+0.52 X 1+0.22 X 2\end{array}$} \\
\hline & & & & & & & 0.22 & & \\
\hline \multirow{3}{*}{$\frac{\hat{2}}{\hat{y}^{2}}$} & \multirow{3}{*}{$\begin{array}{l}\text { X1- Husband smoking } \\
\text { X2-Standing for long time } \\
\text { X3-Carrying heavy object } \\
\text { daily }\end{array}$} & \multirow{3}{*}{0.77} & \multirow{3}{*}{0.593} & \multirow{3}{*}{$59.3 \%$} & \multirow{3}{*}{299.2} & \multirow{3}{*}{$0.001 * *$} & 0.43 & \multirow{3}{*}{2.99} & \multirow{3}{*}{$\begin{array}{c}\text { Preterm }=2.99 \\
+0.43 \times 1+ \\
0.22 \times 2+ \\
0.12 \times 3\end{array}$} \\
\hline & & & & & & & 0.22 & & \\
\hline & & & & & & & 0.12 & & \\
\hline \multirow{4}{*}{ 莺 } & \multirow{4}{*}{$\begin{array}{l}\text { X1- Husband smoking } \\
\text { X2-Standing for long time } \\
\text { X3-Carrying heavy object } \\
\text { daily } \\
\text { X4-Using transportation daily }\end{array}$} & \multirow{4}{*}{0.79} & \multirow{4}{*}{0.624} & \multirow{4}{*}{$62.4 \%$} & \multirow{4}{*}{267.8} & \multirow{4}{*}{$0.001 * *$} & 0.37 & \multirow{4}{*}{2.73} & \multirow{4}{*}{$\begin{array}{c}\text { Preterm }=2.73+ \\
0.37 \mathrm{X} 1+ \\
0.24 \mathrm{X} 2+0.19 \\
\mathrm{X} 3+0.16 \mathrm{X} 4\end{array}$} \\
\hline & & & & & & & 0.24 & & \\
\hline & & & & & & & 0.19 & & \\
\hline & & & & & & & 0.16 & & \\
\hline
\end{tabular}

Multiple logistic regression analysis 
Figure. (1): Current risk factors

Figure. (1): Distribution of women regarding to current risk factors associatedwith pregnancy.

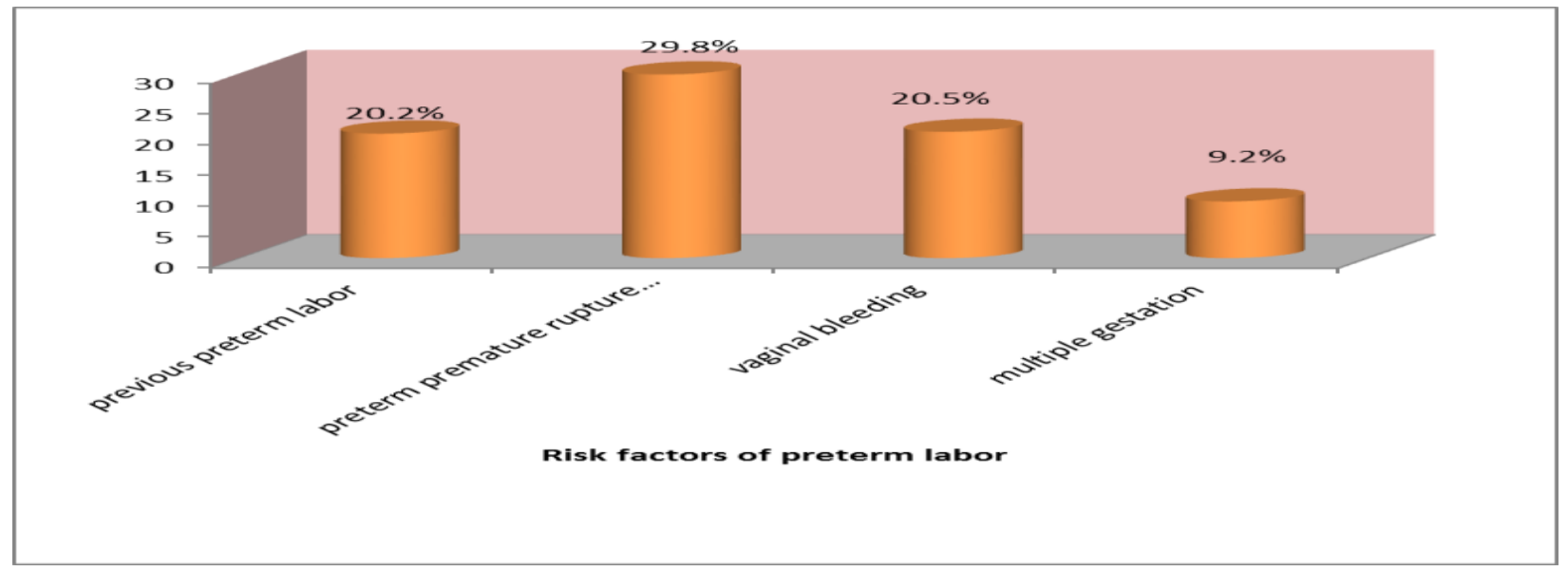

Figure .(2): Risky habits

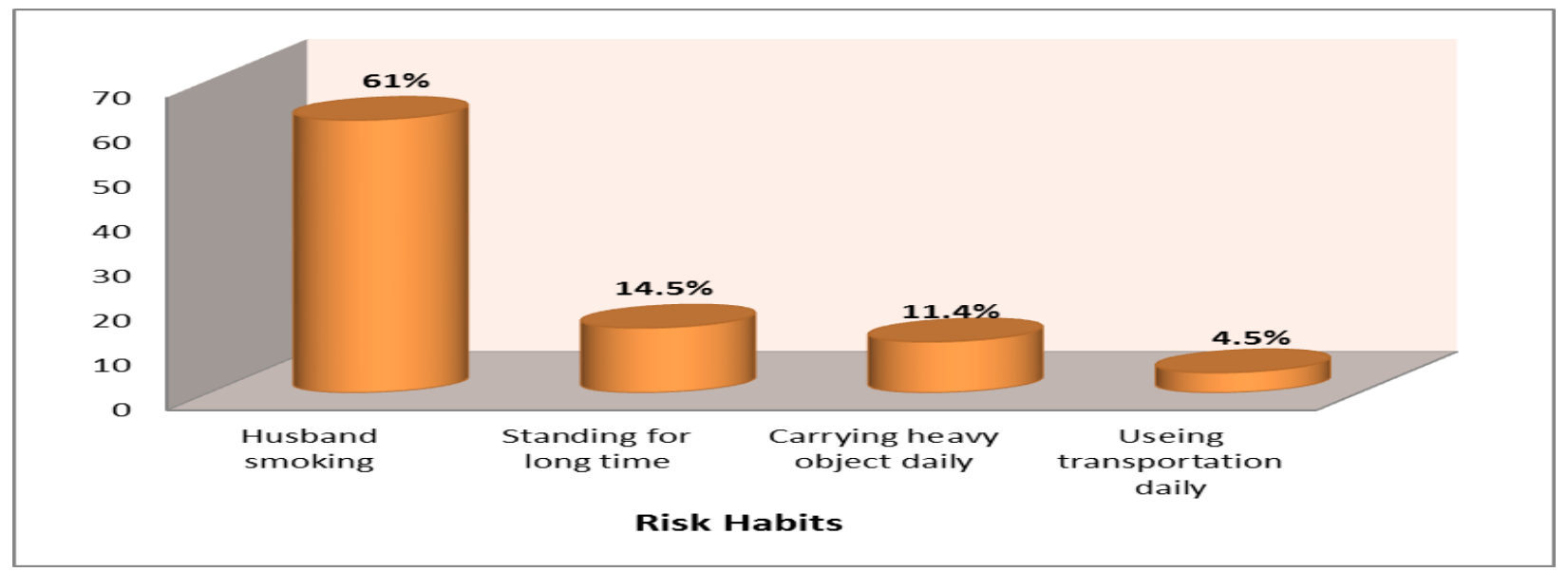

Figure ( 3): Relationship between education and risk factors of preterm labor.

Figure .(3):Relationship between education and risk factors of preterm labor

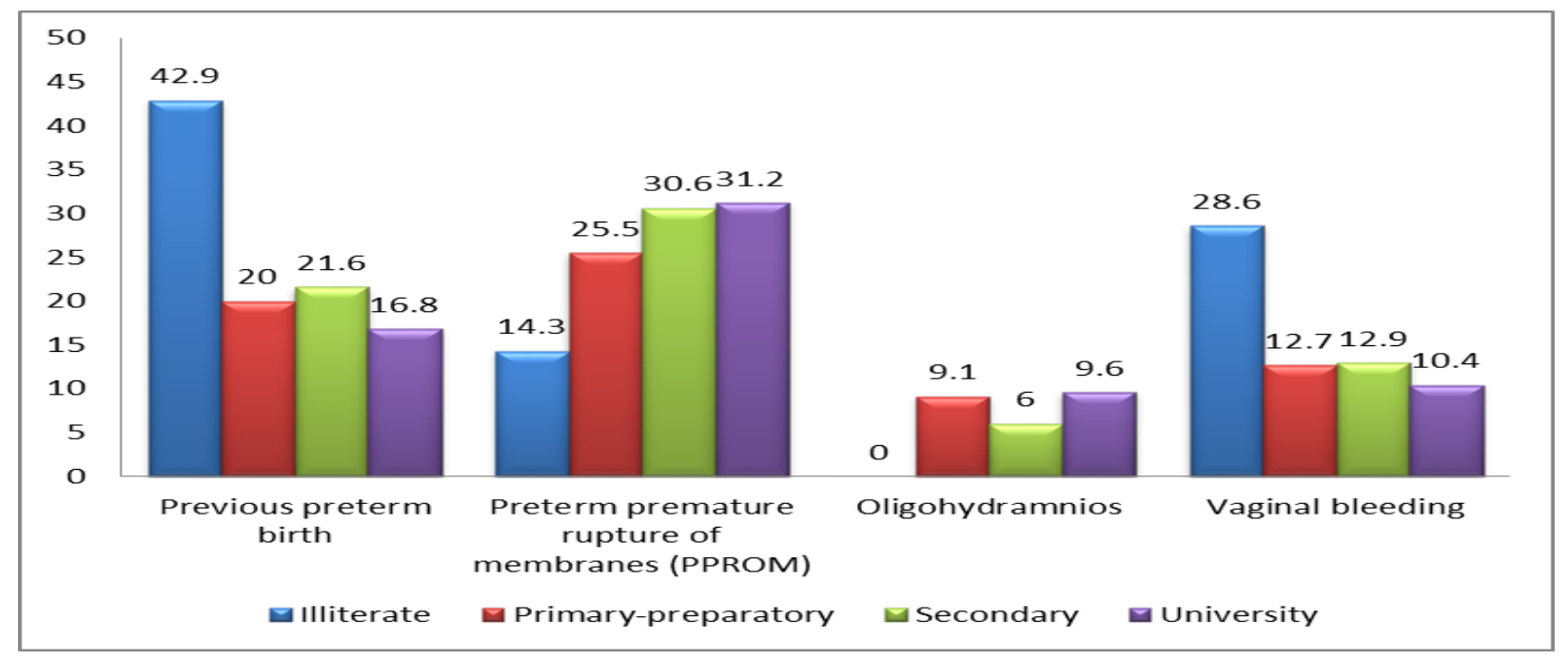


Table (1) : Shows that mean age of pregnant women was $(28.1 \pm 5.7)$ years as regards age group. Regarding to the level of education more than half $(55.2 \%)$ of pregnant women had secondary education .while ( $29.8 \%$ ) of them was university. According to occupation, it was estimated that the majority $(92.9 \%)$ of pregnant women were housewives. As regards to residence more than two third $(67.8 \%)$ of them live in urban areas.

Table (2) : shows past obstetric profile and find that less than half $(49.2 \%)$ of pregnant women are multi gravida and had a history of gravidity from 2 to 4 times. According to Parity, More than one thirds $(39.8 \%)$ are delivered from one to three times. Concerning to history of abortion, nearly two thirds $(64 \%)$ of pregnant women had no history of abortion. The vast majority (94\%) of pregnant women had no history of still birth, According to the history of previous delivery . Nearly one fifth percent $(20.7 \%)$ had a history PROM and less than fifth (18.8\%) had a history of previous preterm labor. Concerning the mode of delivery, the results reveal that more than one-third $(38.8 \%)$ of pregnant women deliver by CSection. More than one thirds (32.9) had birth spacing from 1 to 2 year.

Table (3) : shows current obstetric profile and regarding to that, the majority $(82 \%)$ of pregnant women had gestational age from 34 to 36 month. More than one third $(35.5 \%)$ of the pregnant women had a compliant abdominal pain and Passage of fluids. Regarding to having contraction more than two third $(72.4 \%)$ have a contraction, According to current diagnosis, more than half $(53.8 \%)$ free from diagnosed problem, Concerning to the mode of current delivery, More than two thirds (79.5\%) of them deliver by $\mathrm{C}$-Section

Table (4): Indicates relationships between risk factors and preterm labor such as pPROM, Previous preterm labor, Vaginal bleeding, Multiple gestation and Placenta previa. In which there were high statistically significant difference between preterm labor and these variable at $(\mathrm{p}=0.001)$ respectively and these variable had direct positive relation on preterm labor there variable that were found to be predictor of preterm labor were PPROM represented the first variable that predict preterm labor ,the second step determined the next variable which predict preterm labor that follow the first variable and then third step followed by the fourth step and the same fifth step .At the same time ,the test excluded the variables automatically which couldn't predict preterm labor.

Table (5): Indicates the relationships between preterm labor and some of risky habits such as husband smoking, standing for long time, carrying heavy object, using transportation daily. In which there were statistical significant difference between preterm labor and these variables at $(p=0.001)$ respectively, in which these variable had direct positive relation on preterm labor, The variable that were found to be predictor of preterm labor were husband smoking represented the first variable that predict preterm labor, the second step determined the next variable which predict preterm labor and then third step and finally the fourth step. At the same time, the test excluded the variables automatically which couldn't predict preterm labor.

Figure (1) : shows current risk factors associated with pregnancy, nearly one third (29.8\%) had Preterm premature rupture of membranes (PPROM), More than one fifth of pregnant women $(20.2 \%)$ had Previous preterm birth.

Figure (2) : shows current risk habits associated with pregnancy, the figure reveal that more than two-third $(61 \%)$ of the husband pregnant women had heavy smoke , $(11.4 \%)$ of them carrying heavy object, while $(14.5 \%)$ of pregnant women was standing for long time.

Figure (3) : Shows relationship between pregnant women education and risk factors of preterm labor find that, There are moderate significant relation between previous preterm birth, preterm premature rupture of membrane, Vaginal bleeding and pregnant women education at $(\mathrm{p}=0.001 \%)$. As regards to Oligohydramnios was negatively correlated with pregnant women education at $(\mathrm{p}=0.115)$.

\section{Discussion}

Preterm birth has been the leading cause of neonatal mortality worldwide for about a decade. However, during 2012 new global estimates placed preterm birth as the number two cause of child mortality, behind pneumonia, with more than a million deaths each year. Also during this year, the first national estimates of preterm birth prevalence for 184 countries found that $11 \%$ of the world's babies are born preterm, before 37 completed weeks of gestation, resulting in 15 million babies born too soon (Liu L, et al., 2012).

In Egypt number of preterm births was136,900and preterm birth rate was7.28\% and deaths from complications was 8,100.Thus, preterm birth is a global problem that requires collective and coordinated global action (Blencowe et al., 2012)

Concerning to Socio-demographic characteristics of the pregnant women, the mean age were $(28.1 \pm$ 5.7). Similar finding were reported by (Ananth et al., 2006) who conducted a study to investigate Recurrence of spontaneous versus medically indicated preterm birth and reported that the effect of young maternal age ( $<20$ years) with mean of the maternal age was $(26.2 \pm 6.1)$ years was actually 
significantly for preterm labor. From this study, our findings support previous studies that found preterm deliveries was more common in younger women (age $<20$ years). At the same this results were supported by (Shrim et al., 2011) who conducted a study to investigate Is young maternal age really a risk factor for adverse pregnancy outcome in a Canadian tertiary referral hospital and reported that Teenage mothers also carry an increased risk of adverse pregnancy outcomes including an increased risk of delivering earlier than mothers between 20 to 39 years old .And they are also more likely to have higher rates of extreme prematurity.

However; these finding are contradicted with (Rouget et al., 2013) who carried out study in frence about Medical and sociodemographic risk factors for preterm birth on 1,068 women attending checkup visits at public hospitals between 2004 and

2007 and found that young maternal age (<20 years) was not a risk factor for preterm birth, but older age ( > 35 years) was associated with an increased risk of spontaneous preterm birth.

However in contradiction with the current study finding regarding women's age, (Berkowitz et al., 2008) in their study about the risk factor for preterm labor found that mother with 30 years or older had significantly increase risk for preterm labor.

Concerning women education, in present study more than half of women had secondary education. At the same this result were supported by (Rouget et al., .2013) who carried out study in frence, data do not show any association with mother's education level or duration of pregnancy with preterm labor.

These finding in other hand go opposite with (Brkièeviæ et al., 2013) who conducted a study to investigate Etiological factors of preterm delivery and reported that most prematurely delivered infants were by mothers with primary school education Moreover This result disagreed with( Zhang et al., 2012) who conducted a study about risk factors for preterm birth in Five Maternal and Child Health Hospitals in Beijing ,China and sample was conducted on 1391 women with preterm birth found that Less education $<5$ year were was associated with an increased risk of preterm birth due to lack of knowledge aboutpysiology of pregnancy and risk factor associated with it .

Concerning to occupation of pregnant women the present study found that the majority of sample was housewife. These finding in the same line with (Brkièeviæ et al., 2013) who conducted a study to investigate Etiological factors of preterm delivery and reported that most prematurely delivered infants were by mothers were houswifes due to lack of regular antenatal follow up.
However these finding contradicted with (Kiran et al., 2010) who conducted a study to investigate Predictive value of various risk factors for preterm labor and study sample was conducted on 390 pregnant women admitted in labor from January 2005 to June2006 and reported that heavy work requiring prolonged standing accounted for $40 \%$ of the preterm labor.

According to the women's residence the result of the present study revealed that more than two third of the participated women live in urban area This result agreed with (Zhang et al., 2012) who found that Living in a town or city was associated with a risk of preterm birth than living in a village.

Also this result disagreed with (Iams et al., 2004) who conducted a study to investigate Preterm labor and delivery in Philadelphia and find that living in rural area consider a risk factor for preterm labor due to an available health service and lower scioeconomic status.

According to previous complain during delivery the current study result showed that the majority of women were reported a history of PROM. This implies a high risk of recurrence of preterm labor. This finding in the same line with (Lee , 2003) who conducted a study about Preterm Premature Rupture of Membranes: Risks of Recurrent Complications in the Next Pregnancy Among a Population-Based Sample of Gravid and reported that After a pregnancy that was complicated by preterm premature rupture of membranes, the risk for recurrent preterm premature rupture of membranes is increased by 20 -fold and for recurrent preterm delivery by almost 4-fold.

The second higher percentage of previous obstetric complain was previous preterm labor. This implies a high risk of recurrence of preterm labor. The finding in the line with (Ananth, 2006) who conducted a study about Recurrence of spontaneous versus medically indicated preterm: recognizing the importance of the problem and reported that women with a prior indicated preterm delivery are not only at increased risk for a subsequent indicated PTD, but also for subsequent spontaneous PTD.

According to mode of previous deliverythe results of present study revealed that there are relation between previous cesarean section and preterm labor. The finding in same line (Kennare, 2007) who conducted a study about Risks of adverse outcomes in the next birth after a first cesarean delivery in the South Australian shows that there were a statistically significant association between CS delivery and preterm labor.

The finding in disagreement with ( Brkieeviae, 2013) who found that there were no a statistically significant association between mode of delivery and preterm labor. 
The present study found that more than one-third of pregnant women their last deliveries were from 1 to 2 year. This finding agrees with (Conde - Agudelo, 2006) who conducted a study about Birth spacing and risk of adverse pregnancy out-comes, a meta-analysis on130 articles identified in the searchwho stated that Short inter pregnancy interval ( $<$ six months) increases the risk of PTD.

According to risk factors of preterm labor it can noted from current study that pPROM during pregnancy is a strong risk factor for preterm delivery .These findings agreed with (The Royal College of Obstetricians \& Gynaecologists, 2007) which reported that Preterm Prelabour Rupture of Membranes (pPROM) complicates only $2 \%$ of pregnancies but is associated with $40-45 \%$ of preterm deliveries and pPROM together with spontaneous preterm labor accounts for almost $75 \%$ of all cases of preterm birth.

The second higher percentage of risk factors was previous preterm labor. This implies a high risk of recurrence of preterm labor. The finding in the line with (Ananth, 2006) who conducted a study about Recurrence of spontaneous versus medically indicated preterm: recognizing the importance of the problem and reported that women with a prior indicated preterm delivery are not only at increased risk for a subsequent indicated PTD, but also for subsequent spontaneous PTD.

Also these results agreed with (Zhang, 2012) who reported that occurrence of preterm labor had a significant positive correlation with the recurrence of preterm delivery.

It can noted from current study that vaginal bleeding during pregnancy is a strong risk factor for preterm delivery .This is supported by (Sharami et al., 2013)who conducted a study about The relationship between vaginal bleeding in the first and second trimester of pregnancy and preterm labor in Iran and study sample conducted on 440 pregnant women referred to Al-Zahra Hospital in Rasht, Iran and recognized that vaginal bleeding was associated with 3 times increased risk of preterm delivery also findings showed that bleeding characteristics including bleeding time, frequency, severity and intensity was significantly associated with preterm labor.

The present result illustrates that some of risky habits may be the cause of the majority of extremely preterm deliveries such as smoking. This result in the same line of (Fantuzzi et al., 2007) who conducted a study about Preterm delivery and exposure to active and passive smoking during pregnancy: a casecontrol study from Italy and study sample was 299 preterm cases (including 105 early preterm) and 855 controls were analysed and state that Smoking during pregnancy was strongly associated with preterm delivery.

According to the findings of the current study, it can be observed that standing for long time during pregnancy is a risk factor for preterm labor. these results agreed with (Kiran et al., 2010) who reported that heavy work requiring prolonged standing accounted for $40 \%$ of the preterm labor.

According to the findings of the current study, it can be observed that carrying heavy object during pregnancy is a risk factor for preterm labor according to Mothers who have a lot of physical activity throughout pregnancy are at increased risk for preterm birth and often have babies with low birth weights. This is because physical activity reduces the blood flow to the uterus and sends extra blood to the muscles that are being used. The reduced blood supply to the uterus decreases the flow of oxygen and nutrients to fetus and waste products away from fetus. When the blood supply to the uterus is reduced, both the placenta and fetus don't get enough oxygen and nutrients. Also, a lack of oxygen to the placenta can cause tissue in the placenta to die. 


\section{Conclusion}

The result of this study showed that women delivering preterm babies are affected by a number of risk factors such as preterm premature rupture of membrane ,previous preterm birth and vaginal bleeding and some life style factors such as passive smoking and heavy work. Some of these risk factors may be modified by establishing strategies to educate pregnant women of the adverse pregnancy outcome of this life style factors. Others, such as vaginal bleeding may be remediable if adequate pre- natal care, medical and nursing intervention are sought. Although it is not often possible to avoid certain risk factors predisposing to preterm delivery, their identification is critical in planning the optimum prenatal care and appropriate delivery setting.

\section{Recommendation}

- Based on the results of the present study, the researcher suggested the following recommendations:

1. An education program should be implemented related to result of this study which consider pregnant women who had previous preterm delivery, preterm premature rupture of membrane, vaginal bleeding, smoking remains the most accurate predictors for subsequent preterm delivery.

2. An education program should be implemented for pregnant women about

- Activities that may disturb the cervix and cause labor or infection (e.g., heavy work, long standing, travelling for long distance, lifting heavy object, sexual activity).

- Importanc of nutrition and rest.

- Risk of repeat preterm delivery.

- Importance of have regular Antenatal visit.

3. Improved methods for the identification of women at increased risk of preterm labor both before pregnancy and in the first $\&$ second trimesters are needed.

4. Further studies about preterm labor are needed to validate our results and support our study.

\section{Reference}

1. Ananth C., Vintzileos A., (2006):Medically indicated preterm birth: recognizing the importance of the problem. Clin Perinatol. ;35(1):53-67.

2. American College of Obstetricians \& Gynecologists. (2007):Premature Rupture of Membranes. ACOG Practice Bulletin No.80.Obstet Gynecol;109:1007-1019.
3. Blencowe, H., Cousens, S., Oestergaard, M., et al. (2012). National, regional and worldwide estimates of preterm birth rates in the year 2010 with time trends for selected countries since 1990: a systematic analysis. For CHERG/WHO.

4. Berkowitz G., Blackmore-prince C., Lapinski R.,etal. (2008): Risk factors for preterm birth. Epidemiology; 9:279-285.Child Health Journal $17,6: 1103-11$.

5. Brkièeviæ, E., Grgiæ, G., Ljuca D., et al (2013): Etiological factors of preterm delivery. Journal of Health Sciences ;3(2):159-163.

6. Conde -Agudelo A., Rosas-Bermudez A., Kafury- Goeta A., (2006): Birth spacing \& risk of adverse pregnancy out-comes, a metaanalysis. JAMA;295:1809-1823.

7. Fantuzzi G., Aggazzotti G., Righi E., Facchinetti F., ( 2007): Preterm delivery \& exposure to active \& passive smoking during pregnancy: a case-control study from Italy. Paediatr Perinat Epidemiol. ;21(3):194-200.

8. Goldenberg R., Gravett M., Iams J., et al. (2012): The preterm birth syndrome: issues to consider in creating a classifi cation system. Am JObstet Gynecol 2012, 206:113-118.

9. Iams J., Romero R., Culhane J., Goldenberg R., (2004). "Primary, secondary, \& tertiary interventions to reduce the morbidity \& mortality of preterm birth". The Lancet 371 (9607): 164175.

10. Kiran P., Ajay B., Neena, G., (2010): Predictive value of various risk factors for preterm labor. J Obstet Gynecol India ,60,(2) : pg 141-145.

11. Kennare R., Tucker G., Heard A., Chan A., (2007): Risks of adverse outcomes in the next birth after a first cesarean delivery. Obstet Gynecol. ;109(2 Pt 1):270-6

12. Liu, L., Johnson, H., Cousens, S., Perin, J., Scott, S., et al. (2012). Global, regional, \& national causes of child mortality in 2000-2010: an updated systematic analysis. The Lancet, in press.

13. Lee T., Carpenter M., Heber W., Silver H., (2003): Preterm Premature Rupture of Membranes: Risks of Recurrent Complications in the Next Pregnancy Among a PopulationBased Sample of Gravid Women. Am J Obstet Gyneco;188:209-213.

14. Lawn J., Wilczynska-Ketende K., Cousens S., (2006): Estimating the causes of 4 million neonatal deaths in the year 2000. Int J Epidemiol ; 35: 706-18.

15. Mutambudzi, M., Meyer, J., Warren, N., \& Reisine, S., (2011). Effects of psychosocial characteristics of work on pregnancy outcomes: 
a critical review. Women Health. 51(1), (May 2011), pp. 279-97.

16. Plunkett, J., \& Muglia, L., (2008). Genetic contributions to preterm birth: implications from epidemiological \& genetic association studies. Annals of Medicine, 40(3), 167-195.

17. Your premature baby. March of Dimes Web site.http://www.marchofdimes.com/prematurity/ 21326_1157.asp.Accessed September 7, 2010.

18. Rouget F., Lebreton J., Kadhel P., Monfort C., (2013): Medical \& sociodemographic risk factors for preterm birth in a French Caribbean population of African descent Author manuscript.

19. Shrim, A., Ates, S., Mallozzi, A., Brown, R., Ponette, V., Levin, I., Shehata, F., \& Almog, B., (2011). Is young maternal age really a riskfactor for adverse pregnancy outcome in a Canadian tertiary referral hospital. Journal of Peadiatric Adolescence and Gynaecology. (May 2011).

20. Sharami, S., Darkhaneh, R., Zahiri, Z., Milani F., et al (2013): The relationship between vaginal bleeding in the first and second trimester of pregnancy and preterm labor. Iran J Reprod Med, 11( 5). pp: 385-390.

21. Zhang Y., Liu X., Gao S., Wang J., G., et al. (2012); Risk Factors for Preterm Birth in Five Maternal \& Child Health Hospitals in BeijingDOI: 10.1371/journal.pone.0052780. 